\title{
A LIBRARIAN'S PHILOSOPHY
}

\author{
BY DONALD F. CAMERON
}

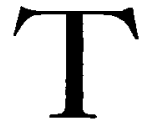

1 HE policies of the Rutgers University Library which I have tried to carry out over the twenty-one years from I 945 to I 966, were inherited rather than established by me. Mr. George Osborn had a policy which was to run the library in such a way as to reduce the barriers between the readers and the books to the lowest possible level. As a result he ran the college library in the early days of the 2oth Century in the way that most colleges and universities have been trying to run them only since the I930's. He managed to operate the library with completely open stacks where the students were free to go to the books on the shelves. In the process of time they were expected to become familiar with the areas which contain the books and periodicals closest to their interest. He established and carried on a system of circulation of books without time limit, and he was able to operate without the application of annoying fines for infractions of the relatively small number of rules.

All of these policies seemed to me to be good. My problem has not been to initiate the policies, but has been in the main to try to adhere to his ideals in spite of the growth and complexity of the University structure and the growth and complexity of the library itself.

To illustrate the problem purely in terms of size we may assume that in 1956 when the central library moved to its new building, which was six times the size of the old one, not only in number of seats, but also in the capacity of the stack, the problem was:- "can you run a large, complex operation on the same simple rules that prevailed in the smaller library?" So far we have managed to keep the barriers between the students and the books to a minimum. The building was indeed built with this kind of operation in mind and in spite of difficulties it still remains the normal procedure in the central Rutgers University Library. It is true that we now have guards at the door who are supposed to examine the books which have been charged out and are about to leave the building. It is also true that we have put a limit of one month to the term of the loan, but in the 
main we still adhere to the principle of the Rutgers University Library as it was put in operation by Mr. Osborn. How completely we have been committed to the policies of Mr. Osborn can be seen in the seating arrangement of the present library where $50 \%$ of the seats are in the stacks themselves and the other $50 \%$ in more conventional large areas such as the reserve reading room and the reference and periodical reading rooms. This mixing of readers and books has been imitated widely and is the standard method of operation in almost all of the libraries which have been built in the last twenty-five years.

In addition to inheriting a policy, I was also fortunate enough to inherit a staff, devoted, intelligent, knowledgeable people able in the ways of my predecessor. Russell VanHorn, Edith Deerr, Ellen Campbell Kelley, Catherine Merritt, Louise C. Benedict, Oliver Westling, Donald Sinclair and H. Gilbert Kelley were already carrying out $\mathrm{Mr}$. Osborn's policies when I joined. Twentyone years later the library still has the benefit of the services of Mrs. Merritt, Mr. Kelley, Mr. Westling, and Mr. Sinclair in addition to those of Miss Higgins and Miss Phillips, who were on the staff previous to my arrival. The debt of gratitude owed to these devoted people by the University for their expert service over the years, great as it is, is small indeed compared to mine. I was the immediate beneficiary of this double heritage of sound policy and the splendid staff.

In a similar way the efforts to build the collection have been in large measure a continuation of the process which started long before I became librarian. Even in the days when Rutgers was very much smaller than it presently is the process of changing from a college to a university was apparent in the development of the collection. For example: Research of the most advanced kind has been going on in the College of Agriculture for over fifty years and the demands upon the book resources of the college had to be met even though the undergraduate program made no such great demands. As the 2oth Century developed research continued mainly in the sciences, but also in other areas of the University besides the College of Agriculture, chiefly in the biology and chemistry departments of the College of Arts and Sciences. Many, many years ago the objectives of the library in supporting the teaching and research 
in those areas were really the objectives of a university library rather than a college library. Meanwhile, what could be called a good undergraduate library was in operation and was satisfactory for the purpose up until shortly after I930. With the growth of research in other areas than the sciences and with the change in the temper of the times throughout the country when the sine qua non for academic promotion became publication, the library has been called upon more and more to support research in all areas. With the spectacular growth of graduate work after 1945 the demands have increased for the building up of the collections in practically all areas. The result has been change in the buying, in the acquisition policies of the library and, of course, in augmenting of the funds made available for books and periodicals.

The change can be measured in another way. In 1945 the amount of money available for books and periodicals throughout the University was less than $\$ 60,000$. In $1964-65$ over $\$ 600$,000 were spent for the same purpose. Now the library has reached a point where it is adding at the rate of 70,000 volumes a year. This growth will continue to accelerate.

It has been my good fortune to be librarian at the time of this expansion and it has given me an opportunity to carry out to some degree in a physical way the ideas which underlay the operation of the Rutgers University Library. As a result in the colleges for men and in Douglass and in Camden and now in Newark, new buildings have been built which, in an architectural way, have attempted to carry out the informal convenient method of operation which endeavors to invite the students to the book shelves and to give them an opportunity of becoming acquainted with books in their own area without close supervision and with a minimum of rules and regulation. In addition, we have been among those who have advocated keeping the library open for long hours, over a hundred hours per week, and until 2 a.m. at examination times in New Brunswick. In the new Library of Science and Medicine which is being planned we expect to have a 24 -hour reading room. In this way we have managed to carry out in a physical way the ideals of the old Rutgers Library.

Some of the difficulties of course, come from sheer pressure of numbers. During I $965-66$ it is our estimate that in an ordinary busy 
day over 4500 people use the Central Library. This number in itself indicates the possibility of noise and confusion in an open shelf library. It also can be assumed that there is a certain amount of confusion on the shelves which are very difficult to bring to a state of order every day.

With over 4000 people in the library a day there is also an excellent chance that books which apparently should be on the shelves are actually in the hands of readers who are scattered throughout the building. Frustrations generated by this situation are made clear to us by indignant patrons. From a certain point of view this is one of the prices we have to pay for our policy. The problem of finding the money for sufficient staff to replace misplaced books promptly on the shelves is another recurring one which we never seem to solve for any great length of time. It is still my opinion that the confusion resulting from the open shelf policy is well worth it, especially from the point of view of students. From time to time it works hardship on the faculty who fail to find what they are looking for on the shelves. We have been generous, however, in supplying duplicates.

The Rutgers University Library, along with all the others, is enjoying a kind of popularity at the present time which was not the case 50 years ago. It is now fashionable not only at Rutgers but everywhere to study in the library. This change in fashion has brought many people who come not to use library resources primarily, but to use their own books. They take up room and on occasion suggestions are made that people who come to the library to use books other than those in the library should not be allowed a seat. Such restriction would be of course against current policy. However, we are still very happy indeed that they come. While they introduce a traffic problem and sometimes a noise problem, nevertheless we rejoice in the popularity which the libraries throughout the university world in America enjoy now. There is no doubt that the libraries will continue to grow and continue to be popular. The problems of management will remain and will grow. These problems are problems of a kind of prosperity unknown in the past. The long tradition of bringing books and students together is still our guide. 